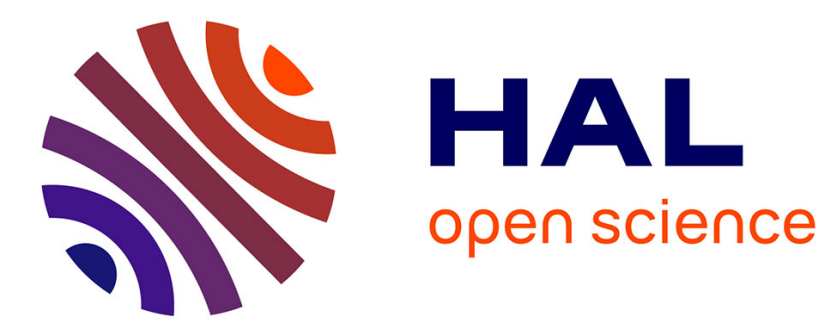

\title{
Connecting Business Processes and Sensor Data in Proactive Manufacturing Enterprises
}

\author{
Sobah Abbas Petersen, Rimmert van Der Kooij, Primoz Puhar
}

\section{To cite this version:}

Sobah Abbas Petersen, Rimmert van Der Kooij, Primoz Puhar. Connecting Business Processes and Sensor Data in Proactive Manufacturing Enterprises. 17th Working Conference on Virtual Enterprises (PRO-VE), Oct 2016, Porto, Portugal. pp.101-109, 10.1007/978-3-319-45390-3_9 . hal-01614612

\section{HAL Id: hal-01614612 \\ https://hal.inria.fr/hal-01614612}

Submitted on 11 Oct 2017

HAL is a multi-disciplinary open access archive for the deposit and dissemination of scientific research documents, whether they are published or not. The documents may come from teaching and research institutions in France or abroad, or from public or private research centers.
L'archive ouverte pluridisciplinaire HAL, est destinée au dépôt et à la diffusion de documents scientifiques de niveau recherche, publiés ou non, émanant des établissements d'enseignement et de recherche français ou étrangers, des laboratoires publics ou privés.

\section{(c)(1)}

Distributed under a Creative Commons Attribution| 4.0 International License 


\title{
Connecting Business Processes and Sensor Data in Proactive Manufacturing Enterprises
}

\author{
Sobah Abbas Petersen ${ }^{1}$, Rimmert van der Kooij ${ }^{1}$, Primoz Puhar ${ }^{2}$ \\ ${ }^{1}$ SINTEF Technology \& Society, Dept of Industrial Management, \\ P.O. Box 4760 Sluppen, Trondheim 7485, Norway \\ ${ }^{2}$ Hella Saturnus Slovenija, Letališka 17, 1001 Ljubljana, Slovenia \\ Email: \{sobah.petersen, Rimmert.VanderKooij\}@sintef.no, \\ Primoz.Puhar@hella.com
}

\begin{abstract}
Real time sensor data is used often to monitor and control industrial applications. Such data is used to detect unexpected events and to take timely action to prevent industrial accidents or breakdowns. We introduce the concept of proactive sensing enterprises. The EU ProaSense project explores the use of real time sensor data and historical data to detect the likelihood of undesired events and to take proactive action to avoid undesired events and improve the resilience of the business. In this paper, we describe how enterprise modelling and process models may be used to connect the key performance indicators and business processes to data from sensors on technical components on the shop floor. We describe the benefits of connecting the business processes to sensor data and how modelling could contribute to reducing maintenance costs, improving proactive decision making and resilience in industry. An example from the manufacturing industry will be described.
\end{abstract}

Keywords: Proactive maintenance, Enterprise Model, Real-time sensor data, Sensing Enterprise, Proactive Enterprise.

\section{Introduction}

Enterprises face high demands to keep production and operations costs low while delivering high quality products and services. The need to deal with unexpected situations and resilience while complying with strict rules on safety aspects are a part of daily operations. The need for enterprises to anticipate what may happen in the future and proactively ensure smooth operations has become a necessity. The decisions that enterprises have to make are often influenced by the situation such as their production targets or their relationship with customers, requiring a careful analysis of the situation and making trade-offs. The need for technological solutions to support such decisions are a necessity for enterprises to meet their current needs. Among these, data and sensors are seen as revolutionary technologies for businesses [1].

Collaborative Networks [2] have been considered as a means of supporting a network of enterprises where enterprises can maintain their competiveness and share knowledge, resources and sometimes risks among each other. Due to the changing nature of business situations, (e.g. the recent decline in the oil industry), enterprises have begun to focus on dealing with disruptions and increasing their resilience to such 
changes [3]. Enterprises have examined several approaches to maintaining their operations and dealing with disruptions and Collaborative Networks have been proposed as a means of effectively dealing with disruptions in enterprises and proposed as a proactive strategy [4]. Collaborative productivity, which can be interpreted as increasing the productivity by collaboration among the cyber (e.g. computing power) and physical (e.g. sensors and hardware) and the networks the enterprise operates within has been identified as important for Industry 4.0 [5]. In addition to maintaining their networks, enterprises also have a need to look within themselves and proactively work to ensure their operations. An important process in manufacturing companies is their maintenance process and the maintenance of their production equipment, as that affects their goals, such as keeping running costs low. Traditionally, maintenance was done at regular intervals or when something happens; reactive maintenance. More recently, predictive maintenance and condition-based maintenance has been practiced by careful inspection of equipment and specific parts. Proactive maintenance goes beyond these methods by taking a systematic approach and examining more than the equipment, but identifying the root cause of a problem and thus avoiding that in a timely manner [6]. Proactive maintenance models have been studied in engineering disciplines [7]. In this paper, we examine the proactive maintenance model of an enterprise, and how proactive decision-making could be supported in enterprises. An overview of proactive decision making models for maintenance is provided in [8].

In the EU ProaSense project, real time sensor data has been used to support proactive maintenance in industry. In this paper, we present ideas from Enterprise Models and how they could support proactivity in enterprises. We describe the maintenance process at HELLA and how real time sensor data on their production line could support proactive maintenance, which could lead to lower running costs and scrap rate. The main aim of the paper is to illustrate the benefits of enterprise models.

This paper is structured as follows: Section 2 describes the EU ProaSense project; Section 3 describes an example case; Section 4 describes the enterprise model and discusses the benefits of modelling and Section 5 summarizes the paper.

\section{ProaSense Project}

The work presented in this paper is a part of the European ICT research project ProaSense (The Proactive Sensing Enterprise) [9]. With the current demands on enterprises such as low production and maintenance costs and higher quality and safety, a new class of enterprise systems, proactive enterprises, that will be continuously aware of what "might happen" in the relevant business context and optimize their behaviour accordingly is essential. ProaSense aims to pave the way for an efficient transmission from Sensing into Proactive enterprises.

The central ideas of the project are focussed on the OODA loop for decision making which consists of Observing a situation, Orienting or making sense of a situation, Deciding on an action to take and Acting [10]. The action taken should also include feedback that is given to the observe phase. The Observe phase is supported by a system consisting of sensors in the environment to access the large amounts of data that are relevant to obtain a good overview of the situation. The Orient phase processes the large 
amounts of real time data as well as the historical data that is available using machine learning techniques. Complex Event Processing is applied to detect events that may indicate the need to act. The Decide phase anticipates events and recommends possible actions that could be appropriate and the Act phase keeps track of the business goals and Key Performance Indicators (KPIs) of the organisation. A software architecture has been designed and implemented (see [11] and [12]) and is currently evaluated by two industrial companies in the oil and gas and manufacturing sectors. The aim is to support proactive maintenance of equipment in the enterprise using real time sensor data.

\section{Manufacturing Industry - An Example Case}

HELLA is a manufacturing company that produces large quantities of lighting technology, such as headlamps, in batches and delivers to the automotive industry. HELLA is interested in the proactive maintenance of their production equipment to support their KPIs, e.g. reduce the amount of downtime of equipment, maintain running stock and improve the quality of their products. The sensor data relevant for HELLA is from their manufacturing equipment on the production line such as the moulds, lacquering stations and ovens. HELLA's aim is to optimize production by reducing the downtime of their production equipment, securing delivery and reducing scrapped products, by detecting early warnings or indications and acting on them in a timely manner. There are several parts of equipment on the production line that could lead to a damaged product leading to scrap; e.g. incorrect parameters on moulding machines. The moulding machine are considered as controlled units as they could automatically correct values that are 'out of line' with the input given via a 'pre-set of golden parameters'.

To achieve proactivity in the maintenance of the equipment, there is a need to anticipate which parameters need to be adapted and when a parameter may deviate from the "golden set" by analysing the data that is available from the sensors and other sources and the trends and patterns to detect potential undesirable situations or events. A simple overview of HELLA's production and maintenance processes and how they relate is shown in Figure 1. One of the sub activities in the maintenance process is to detect an anomaly or a deviation from the normal state, which is detected through the visual inspection of the product that is produced.

Proactive maintenance using sensors placed on the moulding machines could provide input to identify the cause of a problem that could help to mitigate scrapped parts; e.g. the pressure and temperature of the mould or oil, or injection speed. Some of the relevant values could be obtained via real time sensors (hardware) placed on the equipment, while others could be processed or calculated by combining different data sources and through human observations. The latter two are called soft sensors, which include calculated values, values that are input by the humans and values that are derived from documents such as production plans or running stock. 


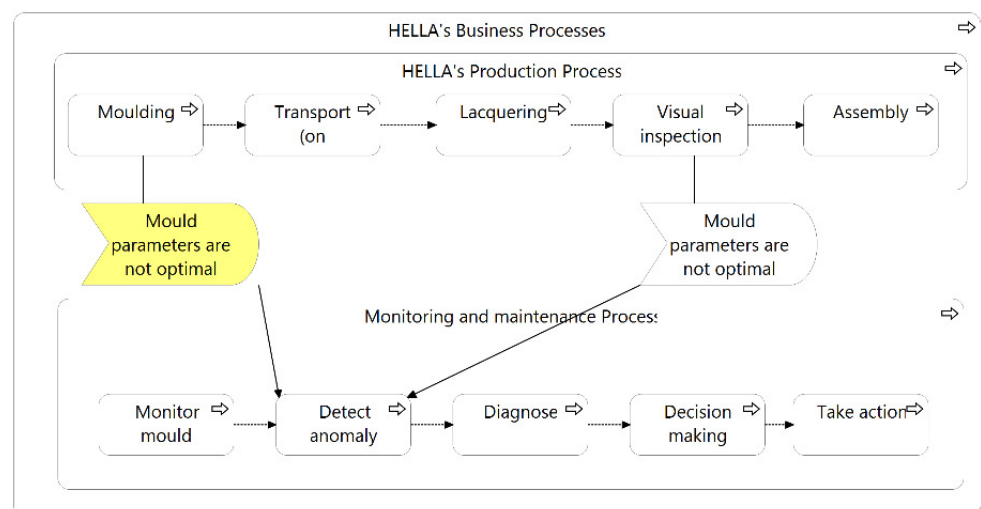

Figure 1 HELLA's production and maintenance processes

In the Observe layer of the OODA conceptual architecture, sensors monitor and gather data on the relevant parameters of the machines which could be used in the Orient layer. The Orient layer detects anomalies based on Complex Event Processing. Here, contextual information is required to make a thorough analysis of the cause of the measured deviation. One of the defects in the products is the appearance of black dots on headlamp lenses. There could be at least three root causes; a jammed cooling line in the moulding machine, high dust level combined with high humidity, or a dirty mould. Sensor data, historical data and contextual information are used to determine the cause. Similarly, in the Decision layer, a set of actions are recommended based on the context such as the production plan, running stock, the product and the customer. For example, there is an upper limit of the scrap rate, which is determined by several factors such as the complexity of the product vs. the production cost, the customer and the status of the production schedule. The decision to take an action and which action to take often depends on the business context.

The enterprise model provides the contextual information that is relevant for the analysis. The model gives an overview of the nearest humidity sensor, the latest maintenance information available for the mould and how long it has been since the last time it was changed. As shown in Figure 1, currently, the detection of defaults in the lenses take place at a later point in time in the production line when a visual inspection is done at the end of the production.

The main roles in the maintenance of HELLA's production line are, Operational Technologist and Setter who adjust and clean the moulds and other equipment, Engineer who fixes the equipment and Maintenance Engineer who is contacted if the problem is too complicated for the Engineer to fix. Depending on the severity of the problem, the level of skill and the number of engineers that are required and the time that will take to solve the problem could increase, leading to increased costs in maintenance and delays in production. 


\section{Enterprise Model}

An information model has been developed to describe the case for HELLA to provide a quick overview of the use case and to provide the overview of the relevant contextual information. We have selected Archimate as our modelling language [13] As it provides comprehensive modelling support for all the perspectives of the proactive sensing enterprise: Business perspective (KPIs, Goals and Actors) and the sensing needs (technical equipment, applications and data).

One of the main business goals of HELLA that is relevant for proactivity is to maintain their running stock, see Figure 2. Two of the KPIs that influence this business goal are the scrap rate of the products and the throughput according to plan (if the planned amount of products are produced during a shift). The scrap rate and the throughput are also related to the overall equipment efficiency such as minimising the downtime of equipment. These values are affected by the running stock for the products; e.g. if the running stock is low, then the tolerance for scrap rate can be higher. The model shows how the link between the business goal to maintain the running stock and how it can link to a particular product (e.g. head lamp and cover lens) and the customer (e.g. customer 1). This information is required to make decision such as to stop a machine and correct the sub-optimal parameters, which would reduce the scrap rate.

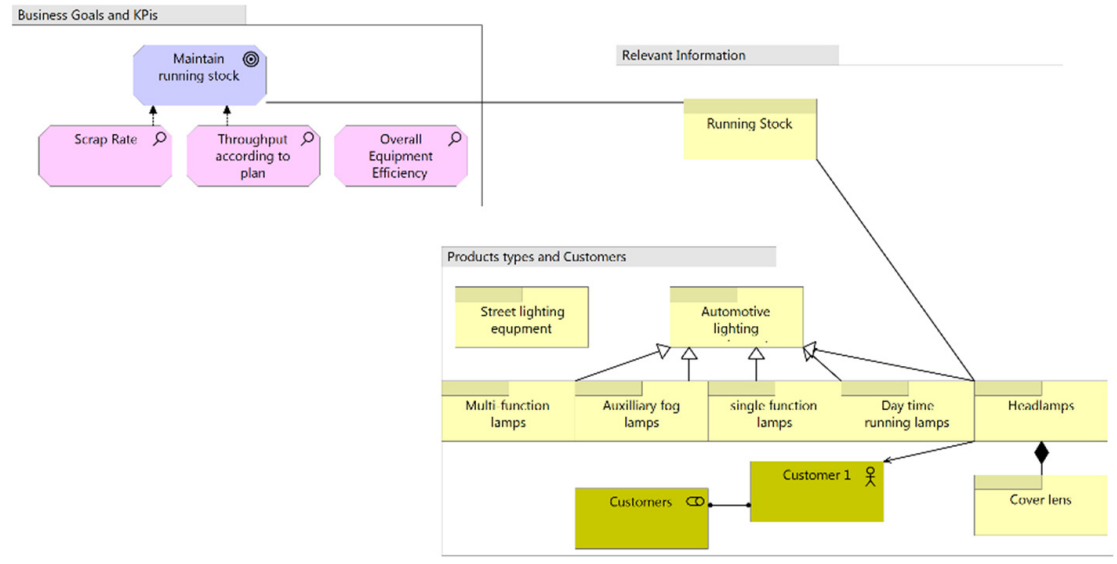

Figure 2 Business Goals and KPIs

An undesirable situation or an anomaly is detected by real time sensor data and other contextual information, see Figure 3. The real time data from sensors is then analysed together with historical data, which can lead to new information and better understanding of the situation; e.g. through detecting patterns that could lead to an undesired event. The data is then used along with historical data (big data analysis) to diagnose the possible root cause and eventually to decide on the action to be taken. When this happens, e.g. as a non-optimal parameter value on a mould which may affect 
the scrap rate, decisions have to be made to either continue producing or to stop the production and attend to diagnose and correct the condition(s) that may lead to faulty products. This decision is based on the target for the production rate for that shift, the current running stock and the percentage of products that are scrapped. For example, the upper limit for the scrap rate is $20 \%$ if the production plan's targets are met and if the production is under achieving (i.e. the production plan targets are not met), the upper limit for the scrap rate can be increased to 30\%. This approach takes the maintenance process beyond monitoring to anticipation of an undesired situation.

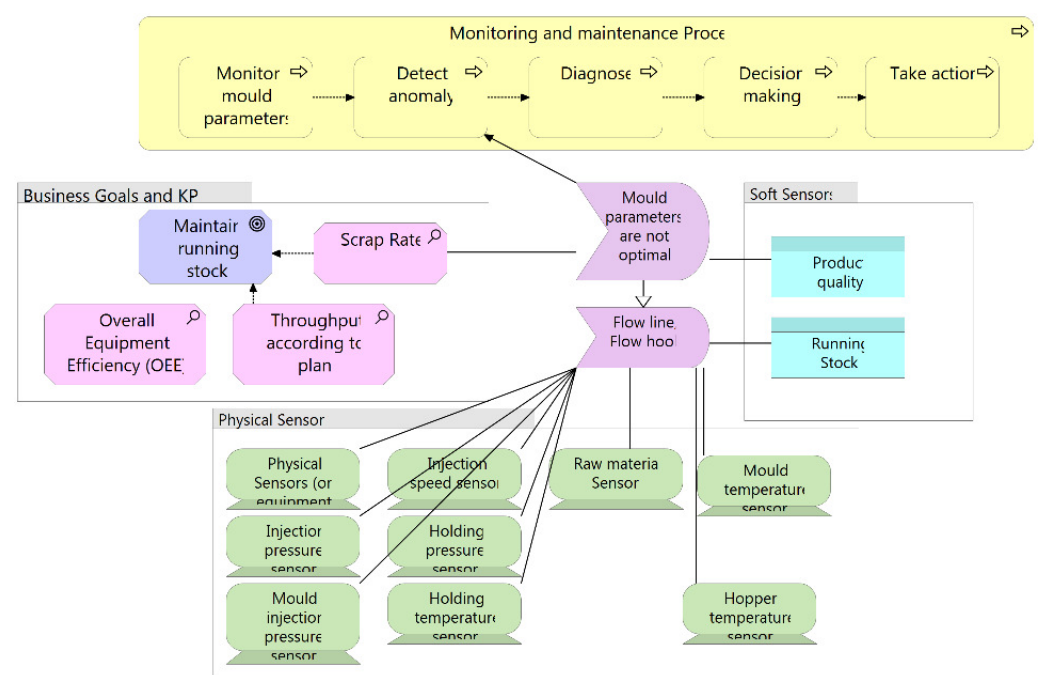

Figure 3 Sensors and Contextual Information for detecting anomalies

The context of the anomaly detected in the Orient phase as shown in Figure 3 is also a part of the contextual information that is relevant for the Decision phase. In addition to the sensor data, information about the sensors, such as their locations, and production related information, the actors that will be involved also influence the set of actions that will be recommended. For example, the Operational Technologist could fix adjustments on the mould while problems on the cylinder will require a Department technologist and their availability may vary.

The enterprise model served the purpose of establishing the relationships between business goals and the sensors and the relevant contextual information as described above. In addition, an Ontology model based on the WWW SSN Ontology [14] was developed for the sensors (physical, human and software) and their contexts, in Protégé. The WWW SSN Ontology was extended by modelling the sensors that are used at HELLA (e.g. sensors to measure humidity, mould temperature, etc.), the locations of sensors which were both on the production equipment (e.g. on moulding machines) and in the surrounding, the products and customers. Other relevant contextual information was modelled as "soft" sensors; e.g. production plan or running stock. To illustrate this, a small part of the Ontology Class structure is shown in Figure 4. 


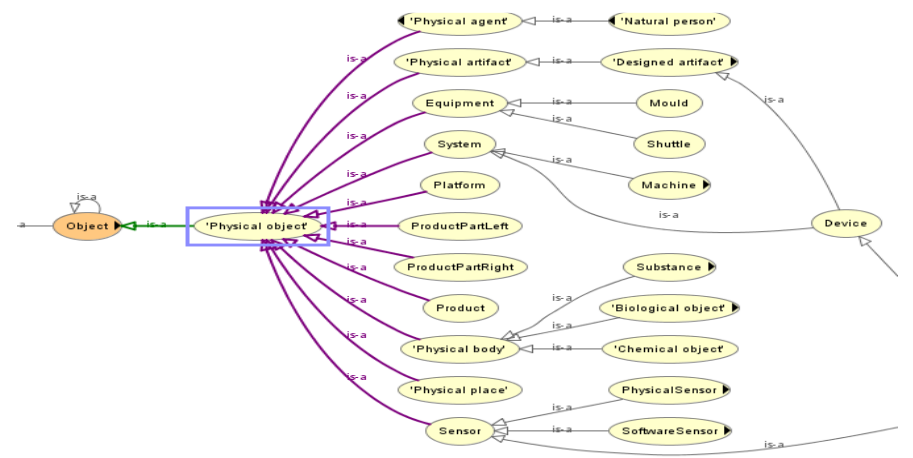

Figure 4 Ontology to include Contextual Information

\section{Discussion and Summary}

The benefits of enterprise modelling is not new and has been the subject of several articles over the years, e.g. [15]. Modelling increases an enterprise's ability to make complex decisions for a number of reasons. It provides a better information and communications base; a property of an enterprise recognised as essential for agility. In the ProaSense project, this property of the enterprise is enhanced in the model by including detailed technical components such as sensors on equipment and how they relate to the business aspects such as the KPIs and business goals. As we saw from the HELLA case, when a potential undesirable event is detected, the decision to stop a machine to fix the anomaly is not always straightforward. It requires the careful consideration of many factors (the context) such as the running stock, the production plan for the shift, the availability of the technician to fix and the customer of the product. In addition, the actions taken must align with the business goals of the company. One of the challenges with data logs alone is to conceptualise them and to relate them to the other business and strategic aspects of an enterprise. The model can facilitate this to support the human in their understanding as well as to provide the relevant and contextualised information for supporting and automating the decision making process and providing recommendations wherever possible.

Proactivity, supported by modelling, can help enterprises improve their level of preparedness and minimise unexpected maintenance costs by avoiding failures and breakdowns. This can affect the Return on Investment (ROI). Proactivity, based on a number of contextual factors, can support better production planning and maintenance of equipment, which contributes to ROI, and return on production. The ability to obtain a better overview and understanding of the total enterprise and the connection within it and other relevant aspects support better decision and proactive maintenance.

The future work will involve the enhancement of the enterprise and ontology (OWL) models and developing the interface between the models and to the rest of the ProaSense software architecture to use the contextual information available from the models in the real time data processing. 


\section{Acknowledgements}

The work was conducted in the EU FP7 project ProaSense. The authors wish to thank the project participants and HELLA for sharing their knowledge and example case.

\section{References}

1. Iansiti, M. and K. Lakhani, R., Digital Ubiquity: How Connections, Sensors, and Data Are Revolutionizing Business. Harvard Business Review, 2014. November 2014

2. Camarinha-Matos, L. and H. Afsarmanesh, Collaborative networks: a new scientific discipline. Journal of Intelligent Manufacturing, 2005. 16: p. 439-452.

3. Camarinha-Matos, L., F. Benaben, and W. Picard, eds. Risks and Resilience of Collaborative Networks. 16th IFIP WG 5.5 Working Conference on Virtual Enterprises PRO-VE. 2015, Springer.

4. Andres, B., R. Poler, and R. Sanchis, Collaborative Strategies Alignment to Enhance the Collaborative Network Agility and Resilience, in Risks and Resilience of Collaborative Networks. 16th IFIP WG 5.5 Working Conference on Virtual Enterprises $P R O-V E$, L. Camarinha-Matos, F. Benaben, and W. Picard, Editors. 2015, Springer. p. 88-99.

5. Schuh, G., et al., Collaboration Mechanisms to increase Productivity in the Context of Industrie 4.0. Procedia CIRP, 2014. 19: p. 51 - 56.

6. EU Systems. The 4 Basic Maintenance Modes. 2014 [cited 201625 April]; Available from: http://www.uesystems.com/mechanical-inspection/the-4-basic-maintenancemodes.

7. Muller, A., M.C. Suhner, and B. Lung, Formalisation of a new prognosis model for supporting proactive maintenance implementation on industrial system. Reliability Engineering and Safety Systems, 2008. 93(2): p. 234-253.

8. $\quad$ Bousdekis, A., et al., A proactive decision making framework for condition-based maintenance. Industrial Management \& Data Systems, 2015. 115(7): p. 1225 - 1250.

9. Proasense. Proasence - The Proactive Sensing Enterprise. 2012 [cited 201625 April]; Available from: http://www.proasense.eu/.

10. Boyd, J., R. The Essence of Winning and Losing, 28 June 1995, a five slide set by Boyd. 1995 [cited 20167 April]; Available from: http://www.danford.net/boyd/essence.htm.

11. Magoutas, B., et al. Anticipation-driven Architecture for Proactive Enterprise Decision Making. in CAiSE-Forum-DC 2014. 2014. Thessaloniki, Greece.

12. Bousdekis, A., et al., A Real-Time Architecture for Proactive Decision Making in Manufacturing Enterprises, in On the Move to Meaningful Internet Systems: OTM 2015 Workshops. 2015, Springer. p. 137-146.

13. Lankhorst, M., Enterprise Architecture at Work - Modelling, Communication and Analysis. 2013: Springer.

14. Semantic Sensor Network Ontology. 201110 June 2011; Available from: http://www.w3.org/2005/Incubator/ssn/wiki/SSN.

15. Leger, J.-B. and G. Morel, Integration of maintenance in the enterprise: Towards an enterprise modelling-based framework compliant with proactive maintenance strategy. Production Planning \& Control: The Management of Operations 2001. 12(2): p. 176-187. 